\title{
FAST COMPUTATION OF TRAIN-INDUCED VIBRATIONS IN HOMOGENEOUS AND LAYERED SOILS
}

\author{
Lutz Auersch ${ }^{1}$ \\ ${ }^{1}$ BAM Federal Institute of Material Research and Testing, 12200 Berlin, Germany \\ lutz.auersch-saworski@bam.de
}

Keywords: Train-induced ground vibration, transfer functions of layered soil, dispersal soil method, frequency-dependant half-space, layer resonance frequency, train speed effects

\begin{abstract}
The computation of the wave propagation in homogeneous and layered soils can be performed by a numerical integration in wavenumber domain. The numerical difficulties of an infinite integral and an integrand with poles can be solved. But if this computation must be repeated for many distances, many frequencies, many loads, or many soil models, it becomes a time consuming task which is not acceptable for a user-friendly prediction tool for railway induced ground vibration. Therefore, an approximate method for the computation of the wave field has been developed. The computation consists of several steps. At first, an approximate dispersion profile is calculated according to rules which have been derived from exact solutions. Secondly, the dispersion is used to achieve the amplitude for a certain frequency and a certain distance by calculating the approximate solution of a corresponding homogeneous half-space. Thirdly, three layer corrections are added which include lowfrequency near-field effects, high-frequency far-field effects, and a resonance amplification around the layer frequency. This procedure yields the wave field due to a point load. For a train load, many of these point-load responses have to be summed up, and a frequencydependant reduction factor has to be multiplied to incorporate the effect of the load distribution along and across the track. - The prediction method is applied to real sites, and the appropriate soil models are identified by approximating the measured transfer functions (frequency-dependant amplitudes) which is presented as an alternative to the approximation of the dispersion (frequency-dependant wave velocities). These examples demonstrate the general behavior of layered soils: the low amplitudes of the stiff half-space at low frequencies, the high amplitudes of the softer layer at high frequencies, the strong increase of amplitudes and a possible resonance amplification at mid frequencies. The material damping of the layer yields a strong attenuation of the amplitudes with the distance for high frequencies. The response depends strongly on the resonance or layer frequency which is shown for different layer depths and velocities always in good agreement with measurements. The layer frequency can be of immense influence if train-speed effects are analysed in a layered soil. The good agreement with many measurements in this contribution as well as in the references [1-4] validates the prediction of ground vibration based on the theory of a layered half-space.
\end{abstract}




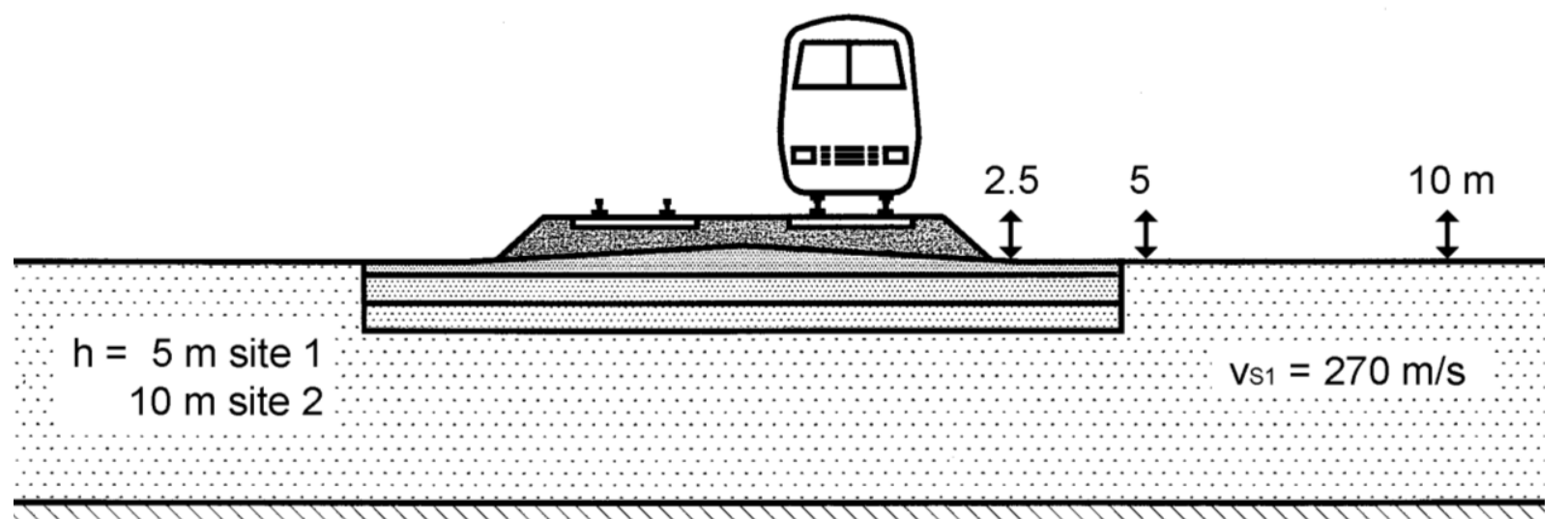

$\mathrm{Vs} 2=1000 \mathrm{~m} / \mathrm{s}$

\section{1}

Figure 1: Train induced ground vibration at a layered soil (sites $\mathrm{W}_{1}$ and $\mathrm{W}_{2}$ near a German high-speed line)

\section{EXACT METHOD FOR THE WAVE FIELD OF LAYERED SOILS}

The compliance $N(f, k)$ of the layered soil is calculated by matrix methods in frequencywavenumber domain [1], and the particle velocity response $v$ at a distance $r$ from a point force $F$ with frequency $f$ follows as the infinite wavenumber integral

$$
\frac{v}{F}(r, f)=f \int_{0}^{\infty} N(f, k) \mathbf{J}_{0}(k r) k d k=H_{P}(r, f)
$$

with the Bessel function $\mathrm{J}_{0}$, and the result $H_{P}$ is also called the transfer (admittance) function. The maxima of the admittance $f N(f, k)$ in frequency-wavenumber domain can also be used to establish the dispersion of the soil model [5].

\section{APPROXIMATE METHODS FOR THE PREDICTION OF TRAIN INDUCED GROUND VIBRATION}

The approximate prediction of train induced ground vibration [6] consists of four parts.

The first part is the dynamic axle load spectrum $F(f)$ which is approximately $1 \mathrm{kN}$ per third-of octave [7]. The second part is a force reduction function due to the distribution of the load across the track width $a$

$$
\frac{F^{\prime}}{F}(f)=\left\{\begin{array}{cc}
\sin a^{*} / a^{*} & \text { for } a^{*} \leq \pi / 2 \\
1 / a^{*} & \text { for } a^{*}>\pi / 2
\end{array} \quad \text { with } \quad a^{*}=\frac{2 \pi f a}{v_{R}}\right.
$$

where $v_{R}$ is the velocity of the Rayleigh wave. The third part is the transfer function of the soil for a train load excitation

$$
H_{T}(x, f)=\sqrt{\sum_{j=1}^{n} H_{P}^{2}\left(\sqrt{x^{2}+y_{j}^{2}}, f\right)}
$$

which is calculated as the sum of the contributions of all $n$ axles at positions $y_{j}$ along the train length $L$ (where $n=40$ and $L=250 \mathrm{~m}$ are used as standard values), and $\mathrm{x}$ is the distance from the track. For each axle, the transfer function of a point load $H_{P}\left(r_{j}, f\right)$ is used. This transfer 
function includes the characteristics of the soil, and its fast approximate calculation is shown in the next section. The prediction of the railway induced ground vibration follows as

$$
v(x, f)=H_{T}(x, f) \frac{F^{\prime}}{F}(f) F(f)
$$

\section{APPROXIMATE DISPERSAL SOIL METHOD}

A two step procedure to calculate approximately the transfer function of a layered soil has been developed. In the first step, the dispersion of the layered soil is approximated, and in the second step, the transfer function of a dispersal soil is approximated. The approximate method is faster and also yields smoother results than the exact method which can sometimes include strong interferences between different wave types.

\subsection{Approximate dispersion}

The exact dispersion curves of layered, multi-layered and continuously layered soils have been used to derive an approximate calculation of the Rayleigh wave dispersion $v_{R}(f)$ from the soil profile $v_{S}(z)$. It is based on the approximated dispersion of a layer on a stiffer half-space with the wave velocities $v_{R 1}$ and $v_{R 2}$

$$
v_{R}(f)=v_{R 1}+\left(v_{R 2}-v_{R 1}\right) 0.5\left(1+\cos \frac{\pi}{2} \frac{f}{f_{1}}\right) \quad \text { with } \quad f_{1}=\frac{v_{S 1}}{3 h_{1}}
$$

which is extended to a multi-layered situation. A correction for each layer is added to the wave speed $v_{R I}$ of the top layer

$$
v_{R}(f)=v_{R 1}+\sum_{i=1}^{n-1}\left(v_{R i+1}-v_{R i}\right) 0.5\left(1+\cos \frac{\pi}{2} \frac{f}{f_{i}}\right) \quad \text { with } \quad f_{i}=\frac{v_{S i}}{3 h_{i}}
$$

$h_{i}$ is the depth where the layer $i$ ends.

\subsection{Approximate transfer functions}

The amplitudes of a homogeneous soil can be approximated by the asymptotes

$$
H_{P}(r, f)=\frac{v}{F}(r, f)=\frac{f(1-v)}{G r} \mathrm{e}^{-D \kappa r^{*}}\left\{\begin{array}{cl}
1 & \text { for } r^{*} \leq r_{0}^{*} \\
\sqrt{r^{*} / r_{0} *} & \text { for } r^{*}>r_{0}^{*}
\end{array} \quad \text { with } \quad r^{*}=\frac{2 \pi f r}{v_{S}}\right.
$$

The upper part of equation (6) describes the near-field and the low-frequency response. At $r^{*}=r_{0} *$ starts the lower part of equation (6), the far field which is dominated by the Rayleigh wave, see [4] for more details.

The amplitudes of a homogeneous soil can be used to calculate the wave-field of an inhomogeneous soil. The amplitudes of the inhomogeneous soil with its dispersion $v_{R}(f)$ are approximated by the amplitudes of a homogeneous half-space, but for each frequency the half-space has a different wave speed - the wave speed $v_{R}(f)$. This method works very well for a soil with continuously increasing stiffness.

If this method is applied to a clearly layered situation, the following modifications must be included:

A frequency-dependent resonance amplification

$$
V=\frac{1}{1+i 2 D_{R} \eta-\eta^{2}}
$$


can be introduced, where

$$
\eta=\left\{\begin{array}{cl}
f / f_{0} & \text { for } f \leq f_{0} \\
2-f / f_{0} & \text { for } f>f_{0}
\end{array} \quad f_{0}=\frac{v_{S}}{3 h} \quad \text { and } \quad D_{R}=\frac{2}{\pi} \frac{\rho_{1} v_{1}}{\rho_{2} v_{2}}\right.
$$

are used for the normalized frequency $\eta$, the resonance frequency $f_{0}$, and the resonance damping $D_{R}$ is calculated according to the 1-dimensional wave theory.

The effect of soft top layers on the low-frequency near-field and the effect of stiff deeper layers on the high-frequency far-field are included by a general procedure. Normally at a certain frequency $f$, the half-space amplitudes of the corresponding wave velocity $v_{R}(f)$ is calculated. Corrections of the transfer functions are made if deeper and stiffer soil material yields greater half-space amplitudes, or softer top layers yield greater "layer amplitudes" which are approximated by $A_{L}=A_{H} \exp (-a r / h)$, according to the low frequency behaviour of a layer on a rigid base. The greatest amplitude is always chosen as the correct transfer function.

It has been observed that the method is improved if a modified dispersion, which is shifted one third of octave to the left, and a minimum resonance damping of $D_{R}=0.1$ is used.

\section{IDENTIFICATION OF THE SOIL MODEL}

\subsection{Wave method}

The dispersion $v_{R}(f)$ of the soil is derived from the measurements by the frequencywavenumber transform method in this contribution, but other methods as the spectral analysis of surface waves SASW or the spatial autocorrelation method SPAC are also in use [5].

The corresponding soil model is found by comparing the calculated dispersion $\tilde{v}_{R}(f)$ for each soil model with the measured dispersion $v_{R}(f)$. The total error for all frequencies is minimized on a grid of soil parameters yielding the soil model that fits best the measured dispersion (grid search algorithm). Instead of calculating the exact dispersion, the approximate dispersion function (6) can be used to achieve acceptable results in short computation time. In addition to the velocity profile $v_{S}(z)$ from the dispersion, the damping $D$ of the soil is evaluated from the measured amplitude-distance relations [5].

\subsection{Transfer function method}

The soil parameters can also be derived from the measured transfer function $H(f, x)$. A high number of transfer functions $\tilde{H}(f, x)$ have to be calculated and compared with the measured transfer function $H(f, x)$. The total error for all distances and frequencies is minimized on a grid of soil parameters yielding the soil model that fits best the measured transfer function (grid search algorithm). This identification procedure yields both, the wave velocities and the damping, and therefore it is more time consuming than the wave method. The simplified calculation of the transfer function can be used to achieve an acceptable computation time.

\section{APPLICATION TO HOMOGENEOUS SOILS}

At first, two examples of homogeneous soils are presented in Figure 2. Measurements have been performed with an electro-dynamic vibrator and a sensor line from $r=2$ to $100 \mathrm{~m}$ distance. The excitation force is measured by the acceleration of the moving mass of $150 \mathrm{~kg}$. A resonance of the vibrator and base-plate mass of $200 \mathrm{~kg}$ is observed by an additional sensor at 50 or $90 \mathrm{~Hz}$. The increased excitation force at and the reduced force above the resonance have been corrected. The smooth transfer functions, the slowly increasing admittances of all distances can be well approximated by a homogeneous soil model. The shear stiffness or shear wave velocity of the soil determines the amplitudes of the wave field. The small 
damping has only little effect on the wave amplitudes. The identified soil parameters $\left(v_{S}=175\right.$ and $250 \mathrm{~m} / \mathrm{s}, D=1.5$ and $2 \%$ ) agree well with those determined by the wave methods (see Table 1).
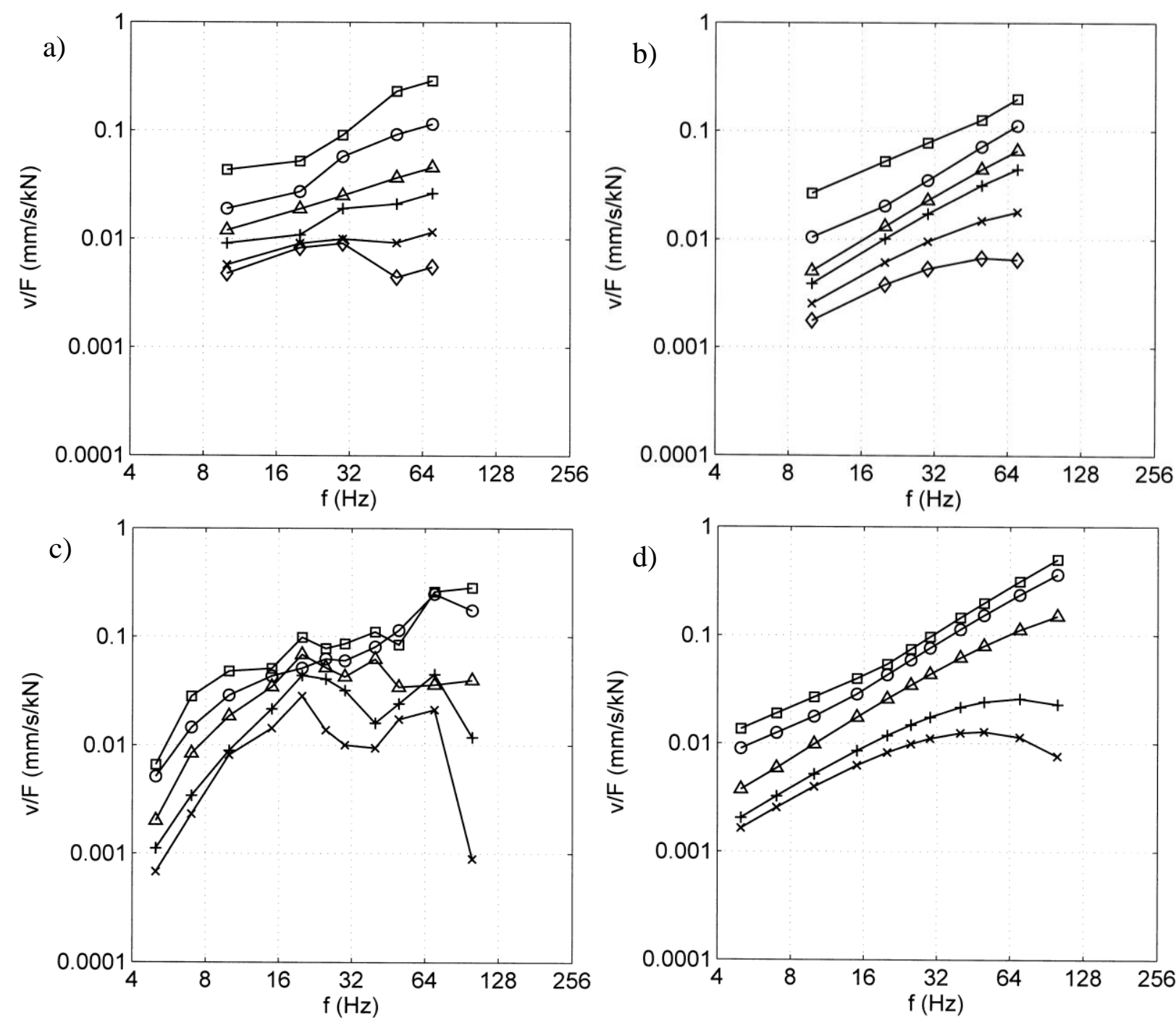

Figure 2: Transfer function measured by vibrator excitation $(\mathrm{a}, \mathrm{c})$ and approximated $(\mathrm{b}, \mathrm{d})$; homogeneous soil at site $\mathrm{M}(\mathrm{a}, \mathrm{b}), r=\square 2, \bigcirc 5, \triangle 10,+15, \times 30, \diamond 50 \mathrm{~m}$, and at site $\mathrm{G}(\mathrm{c}, \mathrm{d}), r=\square 4, \bigcirc 6, \triangle 14,+38, \times 54 \mathrm{~m}$.

\section{APPLICATION TO DIFFERENT LAYERED SOILS}

A total of 11 layered soils are presented in the next three sections and four of them are presented in this section by the following detailed results. The measured transfer functions for hammer excitation are shown in Figures $3 \mathrm{a}$ to $6 \mathrm{a}$ together with the approximating theoretical transfer function (Figs. $3 \mathrm{~b}$ to $6 \mathrm{~b}$ ) where the approximating parameters can be found in Table 1 . The transfer function which is found from the wave measurements is presented in Figures $3 \mathrm{c}$ to $6 \mathrm{c}$ for the point load and in Figures $3 \mathrm{~d}$ to $6 \mathrm{~d}$ for a standard train load. Figures $3 \mathrm{e}$ to $6 \mathrm{e}$ show specific predictions of train vibrations for each site which are compared with the measured train-induced ground vibrations (Figs. 3f to 6f). The stiffest underlying soil has a velocity of $v_{S 2}=1000 \mathrm{~m} / \mathrm{s}$, the softest layer has a $v_{S 1}=75 \mathrm{~m} / \mathrm{s}$. Low layer velocities of $v_{S 1}=100$ to $125 \mathrm{~m} / \mathrm{s}$ have also been found at sites $X_{i} A$, and $V$. The damping values in Table 1 are all in the normal range of $D=1$ to $5 \%$. The damping yields a strong attenuation with distance at 
the high frequencies, and therefore a strong reduction at the far-field points. This can be clearly observed at Figures $4 \mathrm{~b}$ and $6 \mathrm{~b}$ for the sites $\mathrm{D}$ and $\mathrm{X}_{1}$ with the strongest damping of $D=4.5$ and $5 \%$. It should be mentioned that high-frequency amplitudes can be reduced by a stronger damping or by a stiffer soil so that the identification of a soil model is not unique.

$\begin{array}{ccccccc}\text { Site } & v_{S I}(\mathrm{~m} / \mathrm{s}) & v_{S 2}(\mathrm{~m} / \mathrm{s}) & h(\mathrm{~m}) & D(\%) & \text { Method } & \text { Figure } \\ \mathrm{A} & 125 & 350 & 4 & 3.5 & \text { Transfer } & 3 \mathrm{~b} \\ \mathrm{~A} & 150 & 250 & 3.5 & 2 & \text { Wave } & 3 \mathrm{c}-\mathrm{e} \\ \mathrm{D} & 150 & 300 & 2.5 & 4.5 & \text { Transfer } & 4 \mathrm{~b} \\ \mathrm{D} & 325 & 850 & 5 & 2.5 & \text { Wave } & 4 \mathrm{c}-\mathrm{e} \\ \mathrm{G} & 175 & & \text { homogeneous } & 1.5 & \text { Transfer } & 2 \mathrm{~d} \\ \mathrm{G} & 170 & & \text { homogeneous } & 1 & \text { Wave } & {[2]} \\ \mathrm{M} & 250 & & \text { homogeneous } & 2 & \text { Transfer } & 2 \mathrm{~b} \\ \mathrm{M} & 250 & & \text { homogeneous } & 2 & \text { Wave } & \\ \mathrm{O} & 150 & 300 & 1 & 4 & \text { Transfer } & 5 \mathrm{~b} \\ \mathrm{O} & 350 & 1000 & 17 & 1.5 & \text { Wave } & 5 \mathrm{c}-\mathrm{e} \\ \mathrm{U}_{1} & 75 & 500 & 2.5 & 5 & \text { Transfer } & 7 \mathrm{f} \\ \mathrm{U}_{2} & 300 & 700 & 13 & 3 & \text { Wave } & 8 \mathrm{e} \\ \mathrm{V} & 100 & p=0.25 & \text { continuous } & 4 & \text { Transfer } & 9 \mathrm{~d} \\ \mathrm{~V} & 115 & p=0.25 & \text { continuous } & 3.8 & \text { Wave } & {[2]} \\ \mathrm{W}_{1} & 250 & 1000 & 5 & 4 & \text { Transfer } & 9 \mathrm{f} \\ \mathrm{W}_{1} & 270 & 1000 & 5 & 5.9 & \text { Wave } & {[2]} \\ \mathrm{W}_{2} & 270 & 1000 & 10 & 5 & \text { Transfer } & {[8]} \\ \mathrm{X}_{1} & 125 & 350 & 2.5 & 5 & \text { Transfer } & 6 \mathrm{e} \\ \mathrm{X}_{1} & 200 & 500 & 3.5 & 4 & \text { Wave } & 6 \mathrm{c}-\mathrm{e} \\ \mathrm{X}_{1} & 150 & p=0.25 & \text { continuous } & 4.5 & \text { Transfer } & 9 \mathrm{a} \\ \mathrm{X}_{1} & 125 & p=0.4 & \text { continuous } & 5 & \text { Transfer } & 9 \mathrm{~b} \\ \mathrm{X}_{2} & 100 & 250 & 2 & 3 & \text { Transfer } & 7 \mathrm{~b} \\ \mathrm{X}_{2} & 150 & 300 & 3.5 & 2.2 & \text { Wave } & \\ \mathrm{X}_{3} & 125 & 300 & 3 & 4 & \text { Transfer } & 7 \mathrm{~d} \\ \mathrm{X}_{3} & 150 & 350 & 3 & 2.1 & \text { Wave } & \\ \mathrm{Y} & 150 & 300 & 2.5 & 5 & \text { Transfer } & 8 \mathrm{~b} \\ \mathrm{Y} & 180 & 900 & 3 & 6 & \text { Wave } & 8 \mathrm{c} \\ \mathrm{T}_{2} & & & & & & \end{array}$

Table 1: Parameters of the soil models, shear wave velocities $v_{S I}$ and $v_{S 2}$, layer depth $h$ and damping $D$.

\subsection{The characteristics of a layered soil}

The transfer functions of a layered soil for example in Figure 3 show a stronger increase at low and mid frequencies compared to the homogeneous soils in Figure 2. The increase is strongest just below the resonance frequency of the layer, where a small resonance amplification can be observed. The resonance or layer frequencies lie between 10 and $64 \mathrm{~Hz}$ for all measured sites. The lowest resonance frequency corresponds with a thick layer $(h=17 \mathrm{~m}$, Fig. 5b), whereas the highest resonance frequency has been found for a thin layer $(h=1 \mathrm{~m}$, Fig. 5c). For the same thickness $h=2.5 \mathrm{~m}$ of the layer, the softer soil of $75 \mathrm{~m} / \mathrm{s}$ yields the lower resonance frequency of $16 \mathrm{~Hz}$ (site $\mathrm{U}_{1}$, Fig. $7 \mathrm{f}$ compared with site $\mathrm{D}$, Fig. 4b). The resonance amplification can be higher if the velocity contrast of the shear wave is stronger (sites $U_{1}$, Fig. 7 f and Y, Fig. 8a-d). 

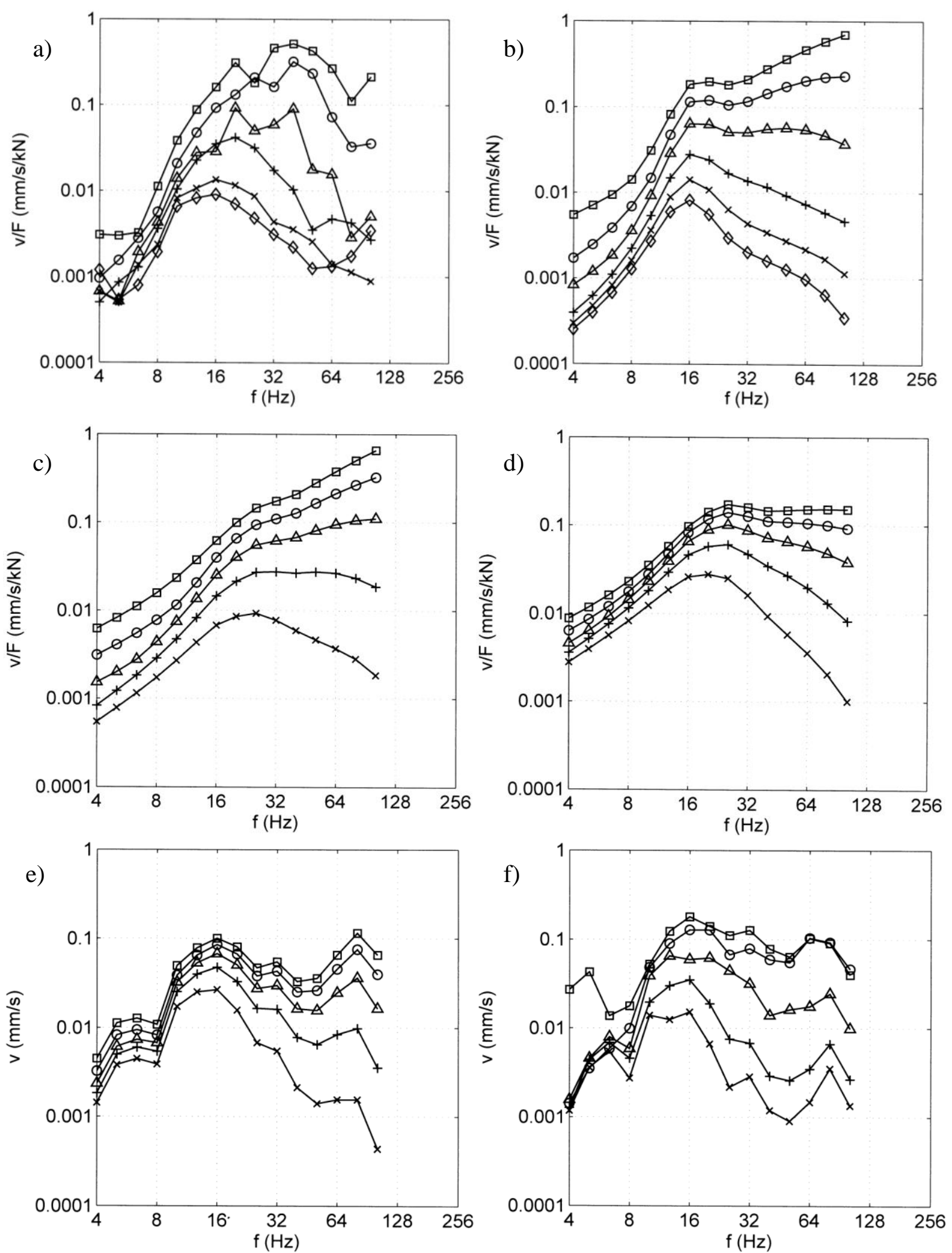

Figure 3: Transfer functions for layered soil at site A, a) measured by hammer excitation, b) approximated, c) for soil model from wave measurements, d) for standard train load; e) specific train prediction and f) measurement of train vibration $(r=\square 4, \bigcirc 8, \triangle 16,+32, \times 48, \diamond 62 \mathrm{~m}, \mathrm{a}-\mathrm{b}, r=\square 4, \bigcirc 8, \triangle 16,+32, \times 64 \mathrm{~m}, \mathrm{c}-\mathrm{f})$ 

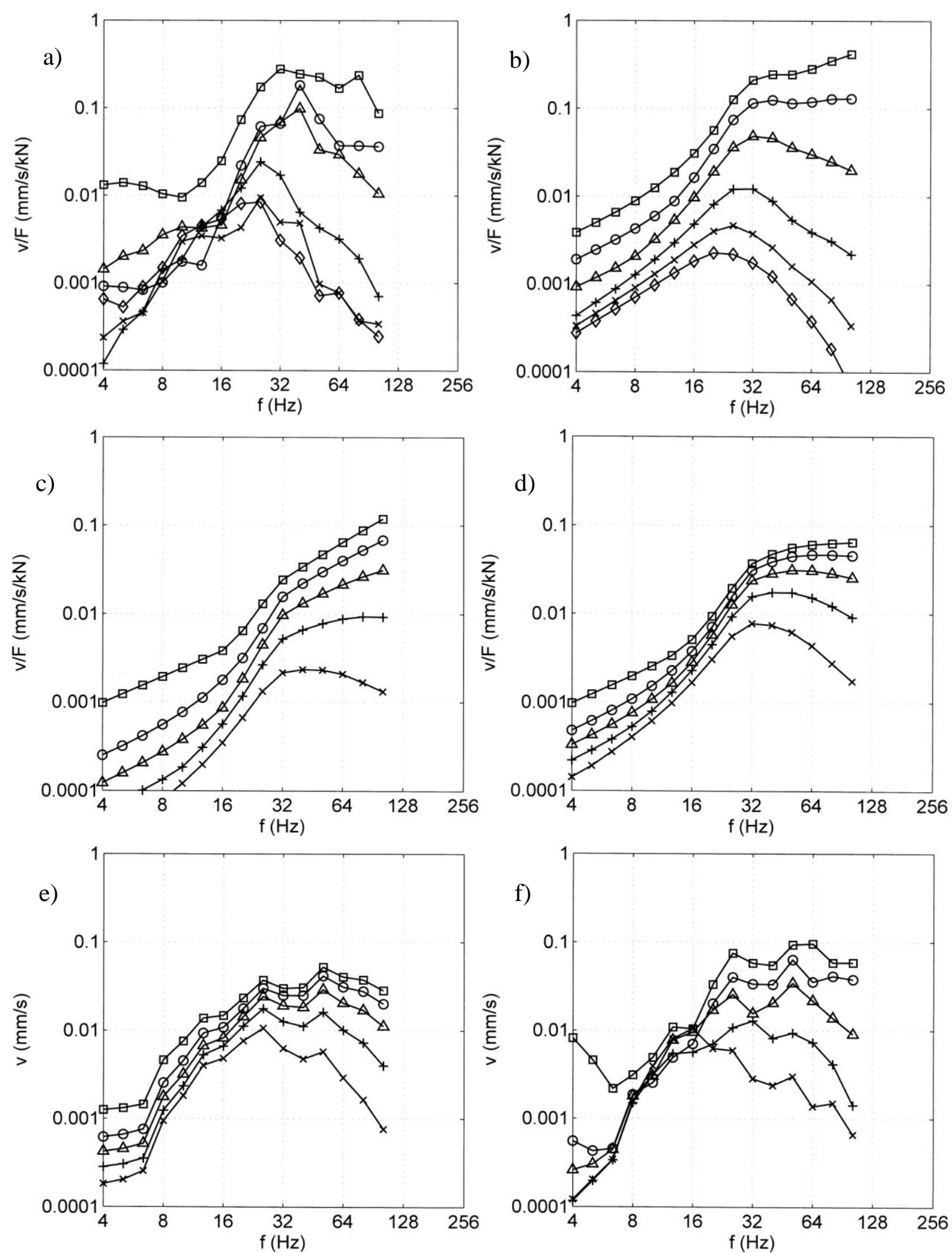

Figure 4: Transfer functions for layered soil at site D, a) measured by hammer excitation, b) approximated, c) for soil model from wave measurements, d) for standard train load; e) specific train prediction and f) measurement of train vibration $(r=\square 4, \bigcirc 8, \triangle 16,+32, \times 48, \diamond 62 \mathrm{~m}, \mathrm{a}-\mathrm{b}, r=\square 4, \bigcirc 8, \triangle 16,+32, \times 64 \mathrm{~m}$, c-f) 

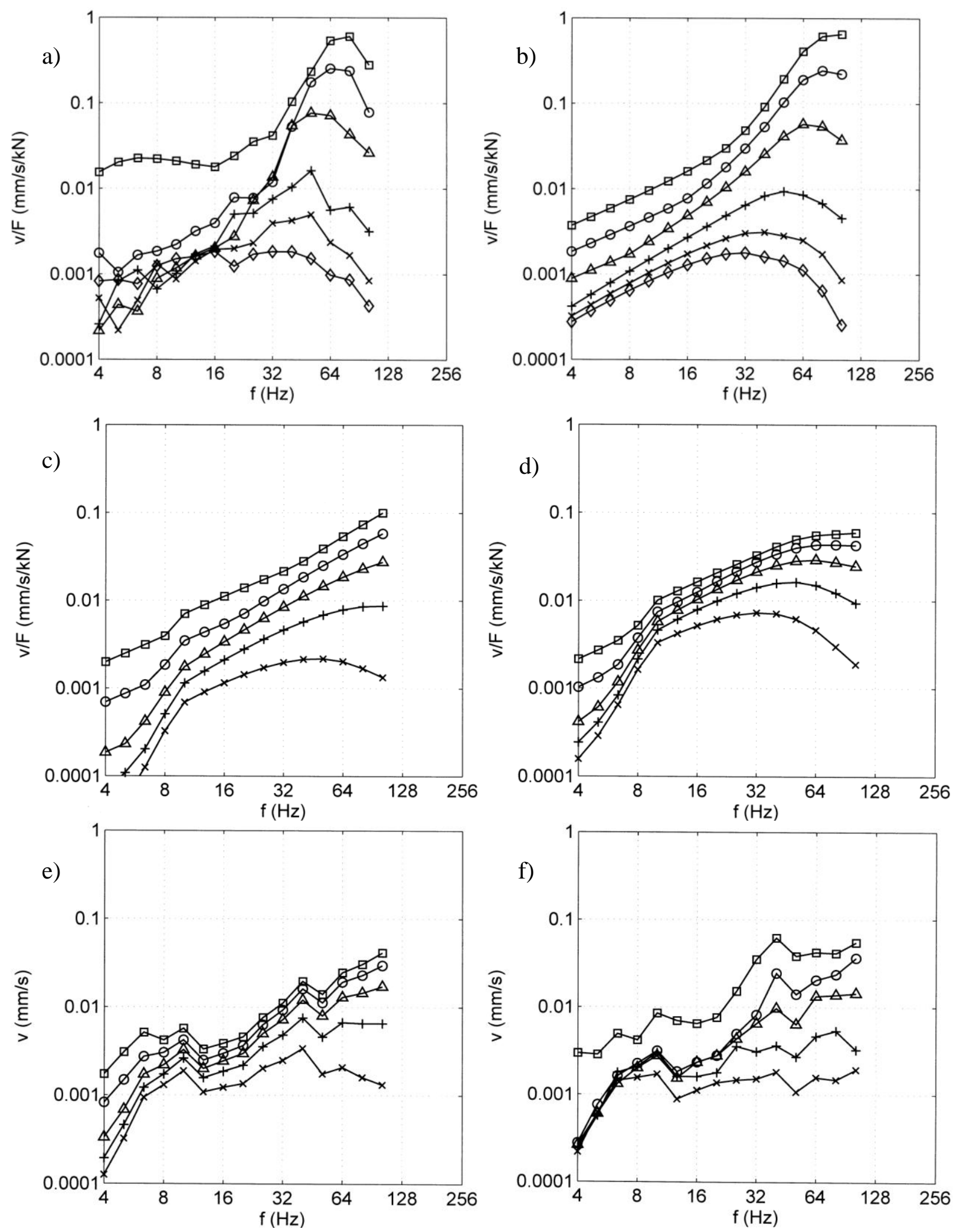

Figure 5: Transfer functions for layered soil at site $\mathrm{O}$, a) measured by hammer excitation, b) approximated, c) for soil model from wave measurements, d) for standard train load; e) specific train prediction and f) measurement of train vibration $(r=\square 4, \bigcirc 8, \triangle 16,+32, \times 48, \diamond 60 \mathrm{~m}, \mathrm{a}-\mathrm{b}, r=\square 4, \bigcirc 8, \triangle 16,+32, \times 64 \mathrm{~m}, \mathrm{c}-\mathrm{f})$ 

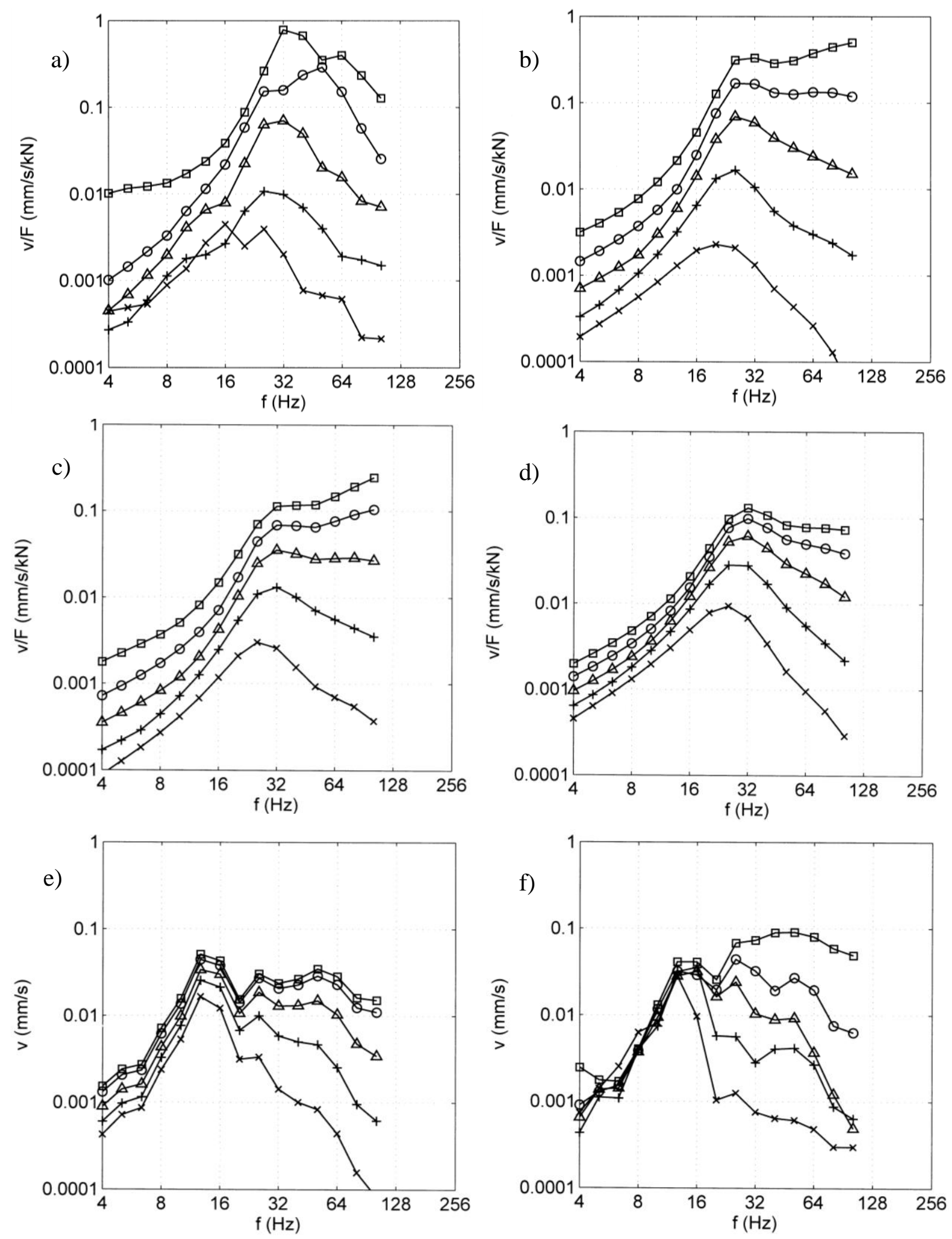

Figure 6: Transfer functions for layered soil at site $X_{1}$ a) measured by hammer excitation, b) approximated, c) for soil model from wave measurements, d) for standard train load; e) specific train prediction and f) measurement of train vibration $(r=\square 4, \bigcirc 8, \triangle 16,+32, \times 48, \diamond 62 \mathrm{~m}$, a-b, $r=\square 6, \bigcirc 8, \triangle 16,+32, \times 64 \mathrm{~m}$, c-f). 


\subsection{Comparison of measurements with the approximate theory}

The approximated transfer functions in Figures $3 \mathrm{~b}$ to $6 \mathrm{~b}$ agree quite well with the measured transfer functions in Figures 3a to 6a. The approximate transfer functions as well as the attenuation with distance are smoother what is beneficial for a robust prediction of railway vibration. Namely the low-frequency low amplitudes are more regular in the approximate theory and compensate possible measurement errors (environmental noise).

\subsection{Comparison of the transfer function for point and train load}

The transfer functions for a point load in Figures $3 \mathrm{c}$ to $6 \mathrm{c}$ show a stronger attenuation with distance than the transfer functions for a train load (Figs. 3d to 6d). This effect is strongest for the low frequencies where only the geometric attenuation occurs. At high frequencies with a strong attenuation due to the damping, the reduction of the geometric attenuation is not so noticeable.

\subsection{Comparison of the predicted and measured train vibration}

The prediction of the train induced ground vibration is done with the transfer functions for a train load (Figs 3d to 6d) and a specific excitation spectrum suited for the measurements. The specific excitation spectrum is always close to $F(f)=1 \mathrm{kN}$ for all thirds of octaves (compare Figures $3 \mathrm{e}$ to $6 \mathrm{e}$ with Figures $3 \mathrm{~d}$ to $6 \mathrm{~d}$ ). The predicted train vibration agrees well with the measured train vibration in Figures $3 \mathrm{f}$ to $6 \mathrm{f}$. The train spectra are rather smooth spectra with only small peaks. The measured low-frequency amplitudes come close together at some sites, in theory there is always a weak attenuation with distance.

\subsection{Comparison of train and hammer excitation}

The measured transfer function and train vibration (Figs $3 \mathrm{a}$ to $6 \mathrm{a}$ and $3 \mathrm{f}$ to $6 \mathrm{f}$ ) generally show a good agreement for all sites (except site $X_{1}$ where the maximum train vibration are found below the resonance frequency of the layered soil). The characteristics of the layered soils are very similar for the hammer and train excitation while the attenuation is stronger for the hammer.

\subsection{Comparison of the transfer and wave method}

The characteristic layer frequencies are very similar for the transfer and wave method (Figs $3 \mathrm{~b}$ to $6 \mathrm{~b}$ and $3 \mathrm{c}$ to $6 \mathrm{c}$ ), $20-25 \mathrm{~Hz}$ at site A, $25-32 \mathrm{~Hz}$ at site $\mathrm{X}_{1}$, and $32 \mathrm{~Hz}$ at site D. At site $\mathrm{O}$ (Fig. 5), both methods identify a stiff soil of $v_{S}=300-350 \mathrm{~m} / \mathrm{s}$ which yields the correct amplitudes in a wide mid-frequency range. A stiffer underlying soil is identified by the wave methods which yields a very low-frequency resonance also observable in the train measurements, whereas the hammer experiments clearly show a high frequency resonance and a softer top layer. Due to environmental noise, the transfer method has some uncertainties at very low frequencies. For site $\mathrm{D}$ and particular for site $\mathrm{X}_{1}$, the transfer functions for both methods are very similar. The amplitudes are a little lower for the wave method, and the high-frequency amplitudes are approximated by a softer layer and a higher damping using the transfer method. The mid-frequency region with the strong increase and the resonance are usually best evaluable in wave and transfer measurements [5]. A generally good agreement at all frequencies has been found for site $\mathrm{A}$. 


\section{MORE EXAMPLES AND CONTINUOUSLY INCREASING SOIL STIFFNESS}

The transfer functions of two more sites $\mathrm{X}_{2}$ and $\mathrm{X}_{3}$, which are not far from site $\mathrm{X}_{1}$, are given in Figure 7 as measurements and theory. In this case, the soil models are very similar,
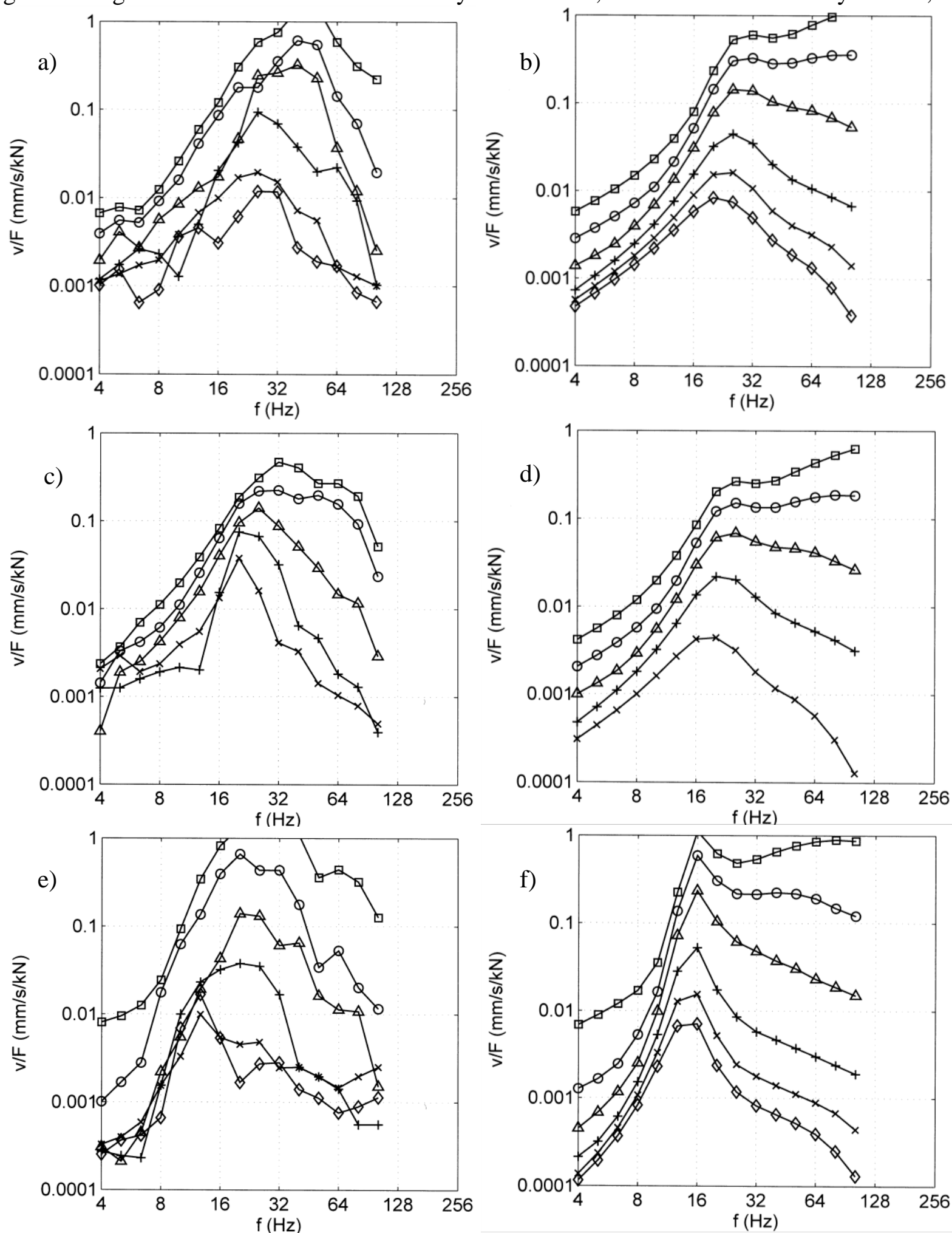

Figure 7: Transfer functions for layered soil at site $\mathrm{X}_{2}(\mathrm{a}, \mathrm{b})$, site $\mathrm{X}_{3}(\mathrm{c}, \mathrm{d})$, and site $\left.\mathrm{U}_{1}(\mathrm{e}, \mathrm{f}), \mathrm{a}, \mathrm{c}, \mathrm{e}\right)$ measured by hammer excitation, b,d,f) approximated, $(r=\square 4, \bigcirc 8, \triangle 16,+32, \times 48, \diamond 62 \mathrm{~m})$. 

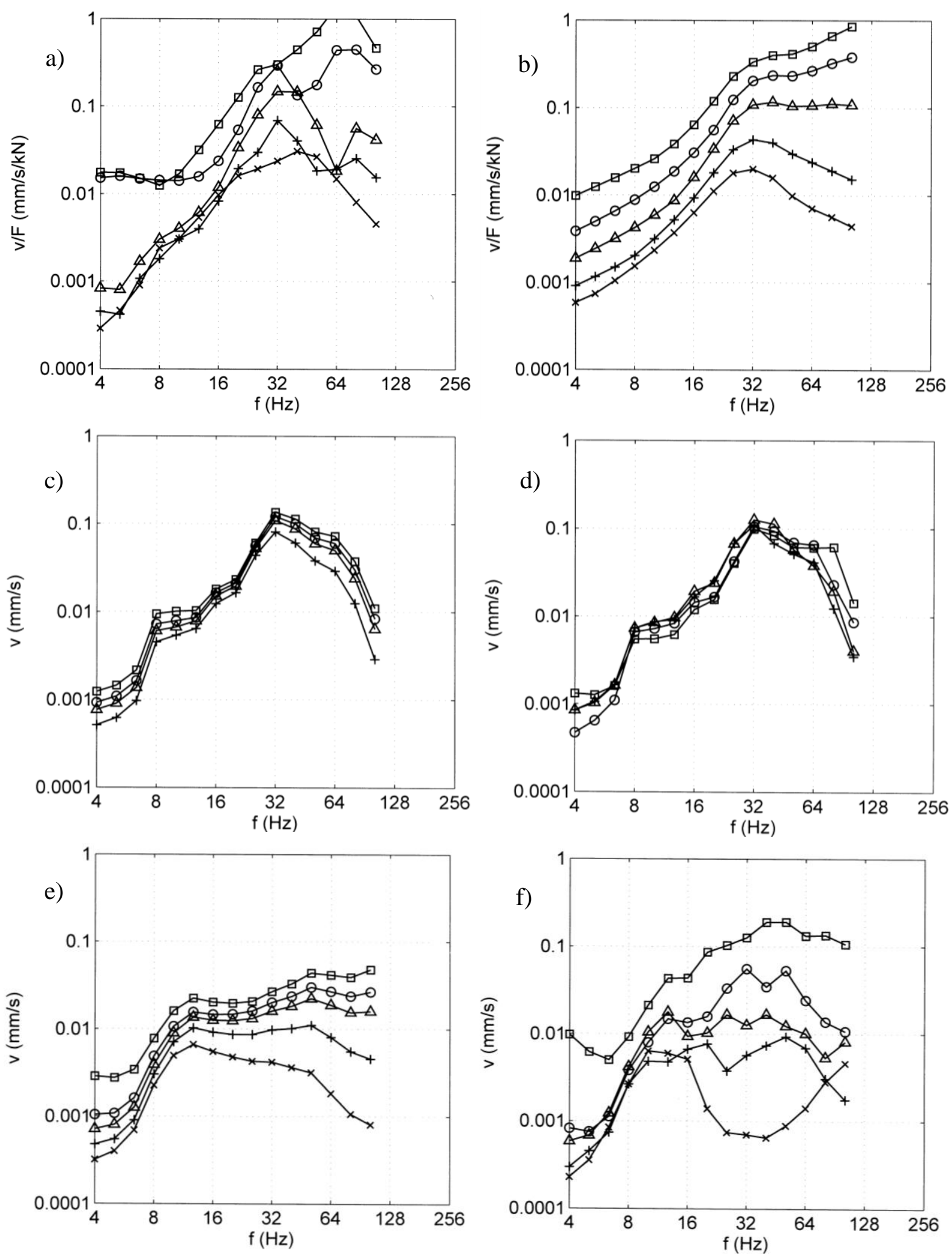

Figure 8: Transfer functions for layered soil at site $\mathrm{Y}(\mathrm{a}-\mathrm{d})$ and site $\left.\mathrm{U}_{2}(\mathrm{e}-\mathrm{f}), \mathrm{a}\right)$ measured by hammer excitation, b) approximated; c,e) specific train prediction and d,f) measurement of train vibration, $(r=\square 2, \bigcirc 4, \triangle 8,+14$, $\times 24 \mathrm{~m}, \mathrm{a}-\mathrm{b}, r=\square 5, \bigcirc 6, \triangle 8,+10, \times 12 \mathrm{~m}, \mathrm{c}-\mathrm{d}, r=\square 4, \bigcirc 10, \triangle 16,+32, \times 64 \mathrm{~m}, \mathrm{e}-\mathrm{f})$. 

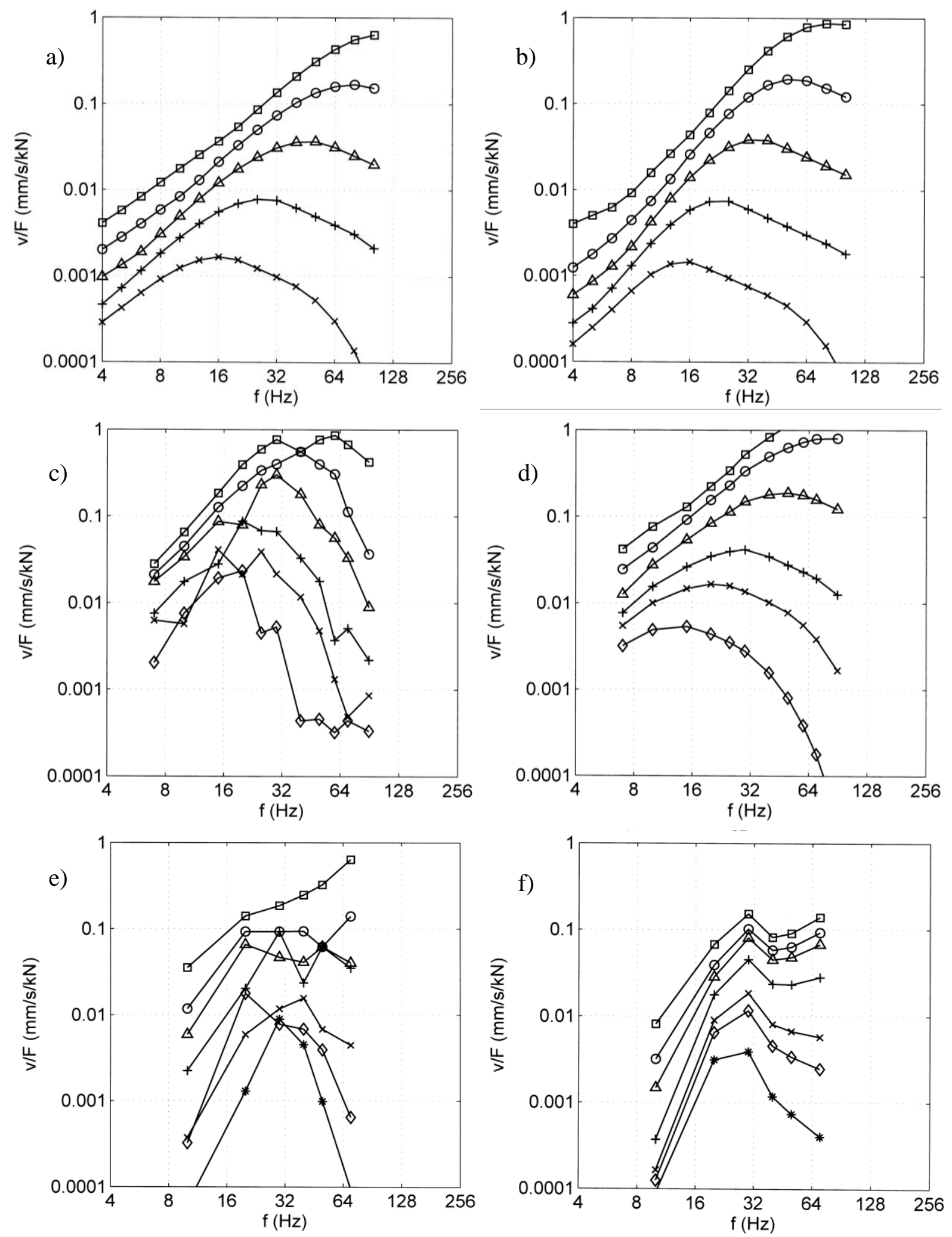

Figure 9: Transfer functions for continuously varying soil at site $\mathrm{X}_{1}(\mathrm{a}, \mathrm{b})$ and site $\mathrm{V}(\mathrm{c}, \mathrm{d})$ and for layered soil at site $\mathrm{W}(\mathrm{e}, \mathrm{f})$, approximated by a) $v_{S} \sim z^{0.25}$, b) $v_{S} \sim z^{0.40}$ (best fit), c) measured by vibrator excitation, d) approximated by $v_{S} \sim z^{0.25}$, e) measured by vibrator excitation, f) approximated, $(r=\square 4, \bigcirc 8, \triangle 16,+32, \times 48$, $\diamond 62 \mathrm{~m}, \mathrm{a}-\mathrm{b}, r=\square 3, \bigcirc 5, \triangle 10,+20, \times 30, \diamond 50 \mathrm{~m}, \mathrm{c}-\mathrm{d}, r=\square 3, \bigcirc 5, \triangle 7,+14, \times 30, \diamond 40 \mathrm{~m}, \mathrm{e}-\mathrm{f})$. 
but this should always be checked experimentally as will be demonstrated in Section 8. Site $\mathrm{X}_{3}$ (Fig. 7c) shows a stronger resonance amplification in the far field. A similar observation is made at site $U_{1}$ in experiment and theory (Figs. 7e,f) and some sites in [2]. Amplitudes higher than $1 \mathrm{~mm} / \mathrm{s} / \mathrm{kN}$ have been measured at this site which correspond with the softest layer material of $v_{S I}=75 \mathrm{~m} / \mathrm{s} \mathrm{x}$. A soft layer yields a low resonance frequency without a great thickness $(h=2.5 \mathrm{~m})$. A soft soil also yields the strongest damping effect, and in addition the damping value $D=5 \%$ is also high for site $\mathrm{U}_{1}$. Therefore a very strong attenuation with distance at high frequencies is observed.

Figure 8 shows measurements and predictions of site $\mathrm{Y}$ where all results show a resonance at $32 \mathrm{~Hz}$, for the hammer as well as for the train excitation. The clear resonance is attributed to the strong velocity contrast $v_{S 1} / v_{S 2}$ between the layer and the underlying half-space. At site $\mathrm{U}_{2}$, the resonance region is well predicted in Figure 8e, but the measured strong attenuation in the following mid-frequency range (Fig. 8f) cannot be represented by the theory. The medium attenuation at high frequencies, however, is in good agreement with the material damping of $D=3 \%$.

The results at site $\mathrm{X}_{1}$ (Fig. 6) are rather smooth, so that a soil with continuously increasing stiffness has also been fitted to the measurements. Figure 9a shows the approximation with the theoretical law $v_{S}(z)=v_{S 1} z^{0.25}$ and Figure $9 \mathrm{~b}$ the result with a higher best-fit power $v_{S 1} z^{0.4}$ which yields a stronger increase with frequency in better agreement with the measurements (Fig. 6a). It can be seen that the layer approximation in Figure 6b is a little better than the continuous approximation.

Figure $9 \mathrm{c}$ shows the results of a vibrator testing at site $\mathrm{V}$ with a continuously increasing stiffness of the soil. The approximating transfer functions in Figure $9 \mathrm{~d}$ agree well with the vibrator measurements as well as with the hammer measurements in [1], and the corresponding model agrees well with the model identified from the wave measurements. Due to the very soft top layer, a rather low resonance frequency of the vibrator on the soil has been found at $30 \mathrm{~Hz}$. This has been confirmed and corrected by stress measurements in the soil below the vibrator.

The layered soil of the next section $\left(\right.$ site $\mathrm{W}_{1}$ ) has also been investigated by vibrator excitation (Fig. 9e). The strong increase of the transfer functions up to $25 \mathrm{~Hz}$ indicates the layered situation with a corresponding resonance frequency. The vibrator resonance at $50 \mathrm{~Hz}$ has been corrected as well as a redistribution of the low amplitudes at $10 \mathrm{~Hz}$ to higher harmonics at 20 and $30 \mathrm{~Hz}$. The transfer-based soil models of this section and namely those from the vibrator experiments are in good agreement with the results of the wave method.

\section{SPEED DEPENDANCY OF THE AMPLITUDES IN LAYERED SOILS}

At the two sites $\mathrm{W}_{1}$ and $\mathrm{W}_{2}$ in only $100 \mathrm{~m}$ distance, trains with different speeds have been measured. At site $\mathrm{W}_{1}$ a strong increase of the amplitudes with train speed has been found whereas the amplitudes remain constant at site $\mathrm{W}_{2}$. The explanation has been identified by the different layering of the soils (Figs 10a,c). Both sites have the same layer and half-space materials, but site $\mathrm{W}_{2}$ has a deeper layer $(h=10 \mathrm{~m})$ compared to site $\mathrm{W}_{1}(h=5 \mathrm{~m})$. This fact yields a lower resonance frequency at $12 \mathrm{~Hz}$ compared to $25 \mathrm{~Hz}$ at site $\mathrm{W}_{2}$.

The ground vibration due to the train passage with $200 \mathrm{~km} / \mathrm{h}$ is shown for both sites in Figure 10b,d. An important component can be seen around $16 \mathrm{~Hz}$ (Fig. 10d) which is dominant in the far field. This component is above the resonance frequency and has high amplitudes for site $\mathrm{W}_{2}$. At site $\mathrm{W}_{1}$ (Fig. 10b), this component is below the resonance frequency and has smaller amplitudes. The maximum amplitudes are rather at the layer resonance than at the mid-frequency excitation. For the speed variation it can be concluded: High and nearly constant amplitudes are observed for different train speeds if the mid- 
frequency range is higher than the resonance frequency. A strong increase of the amplitudes is observed if the mid-frequency component is just in the range of the strong increase before the resonance. These two extreme situations have been met at sites $\mathrm{W}_{1}$ and $\mathrm{W}_{2}$ during the highspeed tests [8].
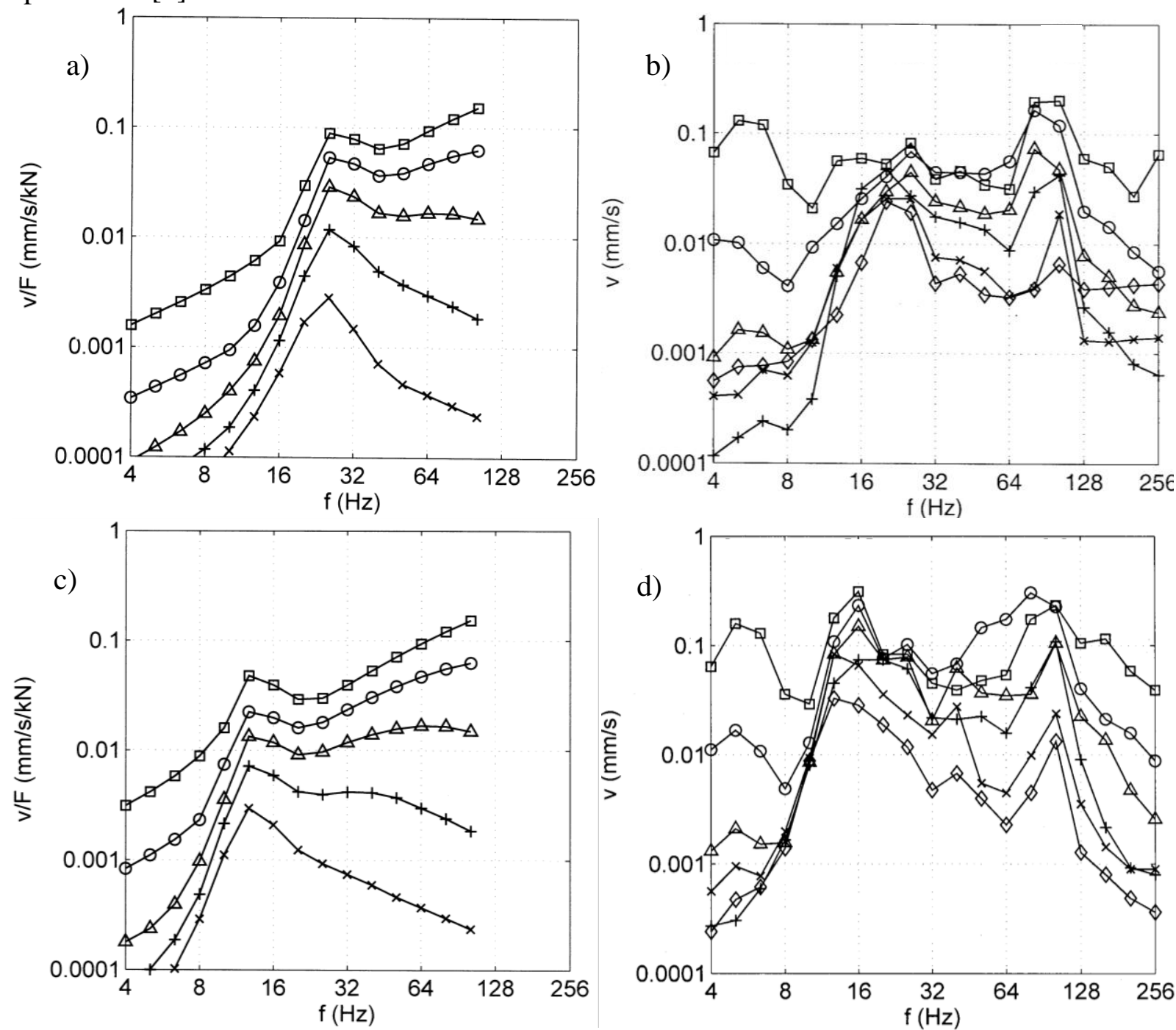

Figure 10: Layered soil at site $\mathrm{W}_{1}(\mathrm{a}, \mathrm{b})$ and $\left.\mathrm{W}_{2}(\mathrm{c}, \mathrm{d}), \mathrm{a}, \mathrm{c}\right)$ approximated transfer functions, $(r=\square 4, \bigcirc 8, \triangle 16$, $+32, \times 64 \mathrm{~m}), \mathrm{b}, \mathrm{d})$ measured train vibration, $(r=\square 2.5, \bigcirc 5, \triangle 10,+20, \times 30, \diamond 50 \mathrm{~m})$.

\section{CONCLUSIONS}

A fast method has been presented to calculate approximately the transfer functions of a layered soil in good agreement with the exact theory. The approximate method has been beneficially used for the identification of a soil model and for the prediction of train-induced ground vibration at 14 real sites, see Table 1 . Whereas two sites consist of an almost homogeneous soil and one site of a soil with continuously increasing stiffness, all other sites clearly demonstrate the typical behaviour of a layered soil. The transfer functions have low low-frequency amplitudes of the stiffer underlying soil and high high-frequency amplitudes of the softer layer. In the mid-frequency range the amplitudes strongly increase and a resonance amplification can occur. The resonance or layer frequency has been found between 10 and $64 \mathrm{~Hz}$ for the different sites, depending on the stiffness and depth of the layer. The influence of the soil has been clearly presented for an example of train vibration, but it is generally 
stronger for hammer excitation. Many items agree well between predicted and measured transfer functions and train vibrations, and between the transfer- and wave-based soil identification, validating thereby the prediction method. Alternative prediction methods are also available which use directly the measured or the exactly calculated transfer functions [4], or calculated force spectra [7].

\section{ACKNOWLEDGEMENT}

The measurements have been performed during the last 30 years. Special thanks to S. Said who participated in almost all measurements and evaluations, to W. Schmid, W. Wuttke, F. Ziegler, M. Manjock, U. Schmidt, and C. Meinhardt for their cooperation in our measurements, and to R. Frenz for his assistance in the soil identification.

\section{REFERENCES}

[1] L. Auersch, Wave propagation in layered soil: theoretical solution in wavenumber domain and experimental results of hammer and railway traffic excitation. Journal of Sound and Vibration, 173, 233-264, 1994.

[2] L. Auersch: Technically induced surface wave fields, Part II: Measured and calculated admittance spectra. Bulletin of the Seismological Society of America, 100, 1540-1550, 2010.

[3] L. Auersch, S. Said: The influence of soil properties on the ground vibration due to railway traffic and other sources - the comparability of different sites. Proc. 6th International Symposium on Environmental Vibration, Tongji University Press, 175186, 2013.

[4] L. Auersch: The use and validation of measured, theoretical and approximated pointload solutions for the prediction of train induced vibration in homogeneous and inhomogeneous soils. International Journal of Acoustics and Vibrations, 19, 52-64, 2014.

[5] L. Auersch, S. Said: Comparison of different dispersion evaluation methods and a case history with the inversion to a soil model, related admittance functions, and the prediction of train induced ground vibration. Journal of Near Surface Geophysics, (2015, accepted).

[6] L. Auersch, W. Rücker: A user-friendly prediction tool for railway induced ground vibrations: Emission - Transmission - Immission. Proc. 9th International Workshop on Railway Noise (IWRN9), München, 1-9 (CD-ROM), 2007.

[7] L. Auersch: Theoretical and experimental excitation force spectra for railway induced ground vibration - vehicle-track soil interaction, irregularities and soil measurements. Vehicle System Dynamics, 48, 235-261, 2010.

[8] L. Auersch: Train induced ground vibrations: different amplitude-speed relations for two layered soils. Journal of Rail and Rapid Transit, 226, 469-488, 2012. 